\title{
The Evaluation of the Body Weight Lowering Effects of Herbal Extract THI on Exercising Healthy Overweight Humans: A Randomized Double-Blind, Placebo-Controlled Trial
}

\author{
Soo Hyun Cho, ${ }^{1}$ Yoosik Yoon, ${ }^{2}$ and Young Yang ${ }^{3}$ \\ ${ }^{1}$ Department of Family Medicine, College of Medicine, Chung-Ang University Hospital, Seoul 156-755, Republic of Korea \\ ${ }^{2}$ Department of Microbiology, College of Medicine, Chung-Ang University, Seoul 156-756, Republic of Korea \\ ${ }^{3}$ Department of Life Science, Sookmyung Women's University, Seoul 140-742, Republic of Korea \\ Correspondence should be addressed to Soo Hyun Cho; soohu@hanmail.net
}

Received 9 December 2012; Revised 14 September 2013; Accepted 14 September 2013

Academic Editor: Menaka C. Thounaojam

Copyright (C) 2013 Soo Hyun Cho et al. This is an open access article distributed under the Creative Commons Attribution License, which permits unrestricted use, distribution, and reproduction in any medium, provided the original work is properly cited.

\begin{abstract}
We investigated the effects of herbal extracts, a mixture of Scutellariae Radix and Platycodi Radix containing the active ingredients Baicalin and Saponin (target herbal ingredient (THI)), on lowering body weight. The present study was a prospective, randomized, double-blind, and placebo-controlled trial carried out at the outpatient department of a hospital over a period of 2 months. Group 1 patients $(n=30)$ received THI, and group 2 patients $(n=23)$ received placebo three times a day before meals. Weight, waist circumference, BMI, total cholesterol, triglycerides, HDL cholesterol, LDL cholesterol, and glucose were measured at baseline and again at the 2nd month. For safety evaluation, various hematological and biochemical parameters were assessed. Values of mean change of weight in the THI-treated group were $-1.16 \pm 1.41 \mathrm{~kg}$ and in the placebo-treated group were $-0.24 \pm 1.70 \mathrm{~kg}$, respectively. The difference in mean change of weight in the THI-treated group compared with that in the placebo-treated group was statistically significant $(P<0.05)$. The incidence of subjective and objective adverse drug reactions was insignificant $(P>0.05)$. THI was statistically significant in its effectiveness on the weight loss.
\end{abstract}

\section{Introduction}

Overweight or obesity substantially raises a patient's risk of morbidity from hypertension $[1,2]$, type 2 diabetes $[3,4]$, dyslipidemia [5], cardiovascular disease (CVD) [5], stroke [6], gallbladder disease [7], osteoarthritis [8], sleep apnea, respiratory problems $[9,10]$, and also endometrial, breast, prostate, and colon cancers [11]. Overweight and obesity are a major public health concern not only in western countries but also in Asian countries because of its increasing prevalence and its association to morbidity and mortality $[12,13]$. The prevalence of obesity (body mass index (BMI) $\geq 30 \mathrm{~kg} / \mathrm{m}^{2}$ ) in USA was $32.2 \%$ in 2004 [14]. While the prevalence of obesity in Asian populations is lower than that of Caucasians, the health risks associated with obesity occur at a lower BMI. Accordingly, the criteria for overweight and obesity in the Asian-Pacific region of WHO has been proposed as BMI $\geq 23 \mathrm{~kg} / \mathrm{m}^{2}$ and BMI $\geq 25 \mathrm{~kg} / \mathrm{m}^{2}$, respectively [15]. The prevalence of obesity using a BMI $\geq 25 \mathrm{~kg} / \mathrm{m}^{2}$ among Koreans over age 19 was $30.8 \%$ in 2010 [16] which represented a rapid increase in comparison to rates in 1998 [17].

There is strong evidence that weight loss in overweight and obese individuals reduces risk factors for diabetes and cardiovascular disease. Strong evidence exists that weight loss reduces blood pressure in both overweight hypertensive and nonhypertensive individuals, reduces serum triglycerides, increases high-density lipoprotein (HDL) cholesterol, and generally produces some reduction in total serum cholesterol and low-density lipoprotein (LDL) cholesterol. Weight loss reduces blood glucose levels in overweight and obese persons without diabetes; weight loss also reduces blood glucose levels and $\mathrm{HbAlc}$ in some patients with type 2 diabetes. Although there have been no prospective trials to show changes in mortality with weight loss in obese patients, reductions in risk factors would suggest that development of type 2 diabetes and CVD would be reduced with weight loss [18]. 
Therefore, drugs or supplements to help weight loss need to be developed.

This study is aimed at investigating the body weight lowering effect of extracts from a mixture of herbs with the active ingredients Baicalin and Saponin (target herbal ingredient (THI)). Baicalin is the active ingredient in Scutellariae Radix (the root of Scutellariae baicalensis) which has been shown to be efficacious in reducing weight, visceral fat mass, serum cholesterol, free fatty acid, and insulin concentrations on high-fat diet-fed rats in comparison to controls [19]. High-fat diet-fed rats were also shown to suppress expected increases in body weight $[20,21]$, plasma triacylglycerols, adipose tissues [20, 22], food consumption, expression of leptin, and neuropeptide Y [21] and prevented hepatic steatosis [22] after consuming saponin isolated from ginseng or Platycodi Radix. The present study was a prospective, randomized, double-blind, and placebo-controlled trial carried out at an outpatient department of the hospital over a period of 2months.

\section{Materials and Methods}

2.1. Study Subjects. Subjects who participated in the study were all healthy volunteers who were recruited using announcements in leaflets and posters at Chung-Ang University Hospital, Seoul, Korea. The study was approved by the Institutional Review Board (IRB) of the Chung-Ang University Hospital (Ethics Committee reference number C2010114 (410)). In addition, written informed consent was obtained from all subjects before initiation of the trial.

From November 2010 to December 2010, a total of 80 patients visited the Outpatient Department of Family Medicine of Chung-Ang University Hospital where they had a baseline clinical examination (weight, BMI, body and composition) and laboratory investigations. Body composition was assessed by a bioelectrical impedance analysis system (InBody 720, Biospace Co., Seoul, Korea) that was developed for the Korean population.

2.2. Inclusion and Exclusion Criteria. The inclusion criteria were patients with $\mathrm{BMI} \geq 23 \mathrm{~kg} / \mathrm{m}^{2}$ of either sex between the age of 18 and 70 years. The following categories of patients were excluded: patients with endocrinologic obesity; patients using other medications that can alter body weight or lipid levels; patients with clinically significant cardiovascular, respiratory, or hepatobiliary disorder; chronic diarrhea; and pregnant or lactating women.

2.3. Preparation of Herbal Dietary Supplement. The dietary supplement, THI, was a liquid herbal extract of Scutellariae Radix and Platycodi Radix as its main ingredient. The two herbs were extracted and made into a dietary supplement by Namil Farm \& Ginseng Co. (Geumsam, Korea). The two herbs were mixed at a 1:1 ratio and extracted with $70 \%$ ethanol. The ethanol was then evaporated under low pressure conditions. The final yield of the herbal extract to raw herbs was $25 \%(\mathrm{w} / \mathrm{w})$. For the standardization of the herbal extract, the contents of Baicalin-an ingredient of
Scutellariae Radix - and Saponin-an ingredient of Platycodi Radix-were measured using high performance liquid chromatography resulting in $5.16 \%$ of Baicalin and $3.95 \%$ of Saponin $(\mathrm{w} / \mathrm{w})$. The preclinical study of this herbal extract was reported previously [22]. Each pouch of THI supplement contained $2.28 \mathrm{gm}$ of herbal extract as its main ingredient, $3.18 \mathrm{gm}$ of oligosaccharide as a sweetener, and $0.05 \mathrm{gm}$ of berry flavor and was adjusted to the final volume of $50 \mathrm{~mL}$ with water. Placebos, with no herbal extract, contained same sweeter and flavor to have a similar appearance and scent.

2.4. Sample Size. There were no previous studies on the efficacy of THI with respect to body weight lowering effects for healthy overweight humans. We postulated that we would need a sample size of $n \geq 36$ in order to see standard deviation and difference of body weight change between groups with a statistical significance level of 0.05 and power of test of 0.9 based on previous animal study [23]. Therefore it was decided to enroll 60 subjects in the study anticipating a $40 \%$ exclusion from the study.

Initially, 69 subjects were enrolled in the study. Fifteen subjects were either disqualified for not complying with the drug regimen or voluntarily dropped from the study. One subject was excluded for excessive exercise. A final sample size of $n=53$ was used in the final analysis and reported in the results.

2.5. Methods and Statistics. A total of 69 patients were enrolled in the study according to inclusion and exclusion criteria and were randomized into two groups of 39 patients for THI and 30 patients for placebo on the computer-generated list by SAS randomization program at Chung-Ang University, College of Medicine, Department of Microbiology. Group 1 patients received THI three times a day before meals. Group 2 patients received placebo three times a day before meals. After enrollment into the study, tests were carried out for baseline clinical examination (weight, BMI, body composition (muscle $(\mathrm{kg})$, fat $(\mathrm{kg})$, and fat ratio (\%)), and blood pressure) and laboratory investigations; hematological tests (red blood cell count, hemoglobin level, (Hb), hematocrit level, white blood cell count, differential white blood cell count, and blood platelet count); blood biochemical tests (total protein, albumin, total cholesterol, HDL cholesterol, LDL cholesterol, triglycerides, blood urea nitrogen, uric acid, serum creatinine, aspartate transaminase (SGOT), alanine transaminase (SGPT), $\gamma$-glutamyl transpeptidase $(\gamma \mathrm{GTP})$, and blood glucose); urine analysis (urine protein, urine sugar, and urinary sediment (erythrocytes, leukocytes, and casts)); and Serologic tests (highly sensitive C-reactive protein (hsCRP), thyroid stimulating hormone (TSH), and free T4)). In the same visit, irrespective of group allotted, all the patients were educated about the importance of lifestyle changes including healthy dietary habits and exercise in weight reduction and maintenance. Patients were given information about the nutritional value of various foods and few simple exercises for decreasing and maintaining near-normal body weight by a clinical dietician. Their compliance for lifestyle change advice was checked through verbal questions at 
each visit. Biochemical examinations assessed were above laboratory investigations (hematological tests, lipid profile, liver function test, blood glucose, serum creatinine, urine analysis, etc.) at baseline, the 1st month, and the 2 nd month of study period. The efficacy of the drug was assessed by primary efficacy parameters, that is, body weight $(\mathrm{kg}), \mathrm{BMI}$ $\left(\mathrm{kg} / \mathrm{m}^{2}\right)$, waist circumference (in $\mathrm{cm}$ measured at midpoint between the lower border of rib cage and iliac crest), and body composition. Other parameters assessed were total cholesterol $(\mathrm{mg} / \mathrm{dL})$, triglyceride $(\mathrm{mg} / \mathrm{dL})$, LDL cholesterol (mg/dL), HDL cholesterol (mg/dL), random blood glucose level (mg/dL), hs-CRP (mg/L), and blood pressure (mmHg). Safety was assessed in terms of both subjective and objective adverse effects with grading scale of Common Terminology Criteria for Adverse Events v3.0 (CTCAE) [24]. Subjective symptoms such as anorexia, nausea, indigestion, loose stools, and constipation were assessed by questioning patients at each visit. Objective signs were assessed by clinical and biochemical examination. Followups were performed at the 1st and 2nd months of the study period, and during each visit, all the efficacy parameters were measured, and safety evaluations were done.

Quantitative data was analyzed by $t$-test or MannWhitney $U$-test for the differences between two means, while qualitative data was analyzed by Chi-square test or Fisher's exact test for difference between two proportions. $P$ value $<$ 0.05 was taken as significant, while $P$ value $>0.05$ was taken as insignificant.

Analyses were performed using the SPSS statistical software Version 12.0KO for windows (SPSS Inc.).

\section{Results}

Nine patients withdrew from trial in the THI-treated group, and 6 patients withdrew from trial in the placebo-treated group because they were busy and had been taking their supplements irregularly. No patients withdrew due to adverse effects of the supplements. In the placebo-treated group, one male patient was excluded because, unlike the rest of the patients, he exercised over 2 hours a day which was too vigorous for the purpose of this study.

At the time of the final analysis, there were 30 patients in the THI-treated group and 23 patients in the placebo-treated group.

Baseline values of both groups were comparable with respect to age, sex, weight, height, BMI, waist circumference, hip circumference, blood pressure, and laboratory investigations (random blood glucose level, total cholesterol, triglyceride, HDL cholesterol, LDL cholesterol, etc.) (Table 1). There were insignificant differences between the two groups except the total bilirubin level $(P<0.05)$.

In the THI-treated group, the mean weight at baseline was $71.84 \pm 10.57 \mathrm{~kg}$ and reduced to $70.68 \pm 10.25 \mathrm{~kg} 2$-months later. In the placebo-treated group, mean weight at baseline was $67.89 \pm 7.85 \mathrm{~kg}$ and reduced to $67.64 \pm 7.96 \mathrm{~kg}$ after 2months.

When the mean value of the change of weight in the THItreated group was compared with that in the placebo-treated group, it was found that the difference in mean change of weight was statistically significant $(P<0.05)$ (Table 2$)$. When values of the mean change of the other clinical examination variables in the THI-treated group were compared with that in the placebo-treated group, the differences were found to be statistically insignificant $(P>0.05)$.

There were no significant $(P>0.05)$ differences in the mean change of blood glucose level, total cholesterol concentration, triglyceride concentration, HDL cholesterol concentration, LDL cholesterol concentration, hs-CRP level, and systolic and diastolic blood pressure during the 2-month treatment in the THI-treated group compared to the placebotreated group (Table 2). All changed laboratory investigations were in normal range.

In the present study, the incidence of adverse drug reactions like nausea (16.7\%), indigestion (26.7\%), abdominal pain $(3.3 \%)$, loose stools $(6.7 \%)$, diarrhea $(13.3 \%)$, constipation $(6.7 \%)$, insomnia $(6.7 \%)$, itching $(6.7 \%)$, satiety $(6.7 \%)$, suppression of appetite (10.0\%), and so forth was insignificant in the THI-treated group compared to the placebo-treated group $(P>0.05)$ (Table 3$)$. Most of these adverse effects were mild and transient. THI had no adverse impact on white blood cell count, hemoglobin, red blood cell count, hematocrit, platelet count, total protein, albumin, total bilirubin, direct bilirubin, SGOT, SGPT, $\gamma$ GTP, blood urea nitrogen, serum creatinine, uric acid, TSH, and free T4 level at the end of study (Table 2).

\section{Discussion}

A sedentary lifestyle coupled with an increased intake of energy-dense food is contributing to the increased prevalence of obesity worldwide. A range of strategies can be employed for weight loss which includes lifestyle changes (diet, exercise), behavioral therapy, pharmacotherapy, and surgery. Orlistat is an effective and well-tolerated antiobesity drug, which can be employed as an adjunct to therapeutic lifestyle changes to achieve and maintain optimal weight [25]. But most antiobesity drugs act on the central nervous system to suppress appetite, reduce food intake, and have serious adverse effects. Therefore, alternative drugs or supplements to help weight loss need to be developed.

In traditional medicine of East Asian countries including China, Korea, and Japan, Scutellariae Radix extracts are widely used for clinical treatment of hyperlipemia, atherosclerosis, hypertension, dysentery, the common cold, and inflammatory diseases such as atopic dermatitis. Baicalin, 5, 6-dihydroxyflavone-7-glucuronic acid, is a major flavonoid found in Scutellariae Radix and is well known for its antiinflammatory and antioxidant activities [26, 27], and few reports describe the antiobesity effects of this compound. In vitro study, Baicalin treatment of 3T3-L1 preadipocytes was shown to inhibit triglyceride accumulation and lipid droplet formation during induced adipogenesis. Baicalin inhibits adipogenesis through the downregulation of proadipogenic genes, including PPAR $\gamma, \mathrm{C} / \mathrm{EBP} \alpha$, and $\mathrm{KLF} 15$, as well as the upregulation of antiadipogenic regulators, including $\mathrm{C} / \mathrm{EBP} \gamma$ and KLF2 [28]. Also in animal studies, Baicalin might have 
TABLE 1: General characteristics of study subjects.

\begin{tabular}{|c|c|c|c|}
\hline Variables & $\begin{array}{c}\text { THI } \\
(n=30)\end{array}$ & $\begin{array}{l}\text { Placebo } \\
(n=23)\end{array}$ & $P$ value \\
\hline \multicolumn{4}{|l|}{ Sex } \\
\hline Male & $3(10)$ & $5(21.7)$ & \multirow{2}{*}{0.272} \\
\hline Female & $27(90)$ & $18(78.3)$ & \\
\hline Age (years) & $42.90 \pm 12.67$ & $41.83 \pm 14.82$ & 0.778 \\
\hline Height $(\mathrm{cm})^{*}$ & $159.22 \pm 7.91$ & $160.03 \pm 9.46$ & 0.654 \\
\hline Weight (kg) & $71.84 \pm 10.57$ & $67.89 \pm 7.85$ & 0.139 \\
\hline Body mass index $\left(\mathrm{kg} / \mathrm{m}^{2}\right)$ & $28.35 \pm 3.95$ & $26.51 \pm 2.21$ & 0.050 \\
\hline Waist circumference $(\mathrm{cm})$ & $84.02 \pm 8.66$ & $82.96 \pm 6.61$ & 0.628 \\
\hline Hip circumference $(\mathrm{cm})^{*}$ & $102.79 \pm 7.09$ & $99.40 \pm 3.97$ & 0.337 \\
\hline Waist/hip (\%) & $81.75 \pm 6.51$ & $83.50 \pm 6.28$ & 0.329 \\
\hline \multicolumn{4}{|l|}{ Body composition } \\
\hline Muscle $(\mathrm{kg})^{*}$ & $42.60 \pm 7.91$ & $41.14 \pm 8.07$ & 0.355 \\
\hline Fat (kg) & $26.68 \pm 7.94$ & $24.43 \pm 4.24$ & 0.225 \\
\hline Fat ratio $(\%)$ & $36.90 \pm 7.81$ & $36.28 \pm 6.48$ & 0.759 \\
\hline \multicolumn{4}{|l|}{ Blood pressure (mmHg) } \\
\hline Systolic & $124.80 \pm 13.66$ & $125.17 \pm 13.58$ & 0.922 \\
\hline Diastolic* & $85.47 \pm 10.18$ & $84.74 \pm 9.79$ & 0.842 \\
\hline Blood glucose $(\mathrm{mg} / \mathrm{dL})^{*}$ & $94.73 \pm 11.43$ & $96.00 \pm 6.19$ & 0.570 \\
\hline Total cholesterol (mg/dL) & $197.20 \pm 38.39$ & $201.39 \pm 39.83$ & 0.700 \\
\hline Triglyceride $(\mathrm{mg} / \mathrm{dL})^{*}$ & $115.03 \pm 76.11$ & $117.57 \pm 56.93$ & 0.341 \\
\hline HDL cholesterol (mg/dL) ${ }^{*}$ & $49.97 \pm 9.04$ & $54.04 \pm 12.55$ & 0.261 \\
\hline LDL cholesterol (mg/dL) & $117.67 \pm 31.76$ & $115.91 \pm 28.30$ & 0.836 \\
\hline hs-CRP (mg/L)* & $0.92 \pm 0.88$ & $2.41 \pm 6.52$ & 0.495 \\
\hline White blood cell count $\left(10^{\wedge} 9 / \mathrm{L}\right)^{*}$ & $5.99 \pm 1.37$ & $6.72 \pm 1.56$ & 0.097 \\
\hline Hemoglobin (g/dL) & $13.69 \pm 1.23$ & $14.11 \pm 1.42$ & 0.262 \\
\hline Hematocrit $(\%)^{*}$ & $41.03 \pm 3.25$ & $42.22 \pm 3.65$ & 0.274 \\
\hline Platelet count $\left(10^{\wedge} 9 / \mathrm{L}\right)^{*}$ & $256.97 \pm 43.91$ & $255.87 \pm 45.20$ & 0.641 \\
\hline Total protein $(\mathrm{g} / \mathrm{dL})$ & $7.26 \pm 0.25$ & $7.42 \pm 0.42$ & 0.091 \\
\hline Albumin $(\mathrm{g} / \mathrm{dL})^{*}$ & $4.32 \pm 0.25$ & $4.36 \pm 0.25$ & 0.562 \\
\hline Total bilirubin $(\mathrm{mg} / \mathrm{dL})^{*}$ & $0.58 \pm 0.16$ & $0.74 \pm 0.29$ & $0.029^{\ddagger}$ \\
\hline Direct bilirubin $(\mathrm{mg} / \mathrm{dL})^{*}$ & $0.17 \pm 0.05$ & $0.21 \pm 0.08$ & 0.091 \\
\hline SGOT $(\mathrm{IU} / \mathrm{L})^{*}$ & $23.10 \pm 7.22$ & $21.30 \pm 5.49$ & 0.335 \\
\hline SGPT $(\mathrm{IU} / \mathrm{L})^{*}$ & $25.77 \pm 14.86$ & $22.17 \pm 13.00$ & 0.243 \\
\hline$\gamma \mathrm{GTP}(\mathrm{IU} / \mathrm{L})^{*}$ & $32.53 \pm 29.19$ & $24.65 \pm 15.08$ & 0.596 \\
\hline Blood urea nitrogen $(\mathrm{mg} / \mathrm{dL})^{*}$ & $13.33 \pm 3.16$ & $13.70 \pm 3.75$ & 0.704 \\
\hline Serum creatinine $(\mathrm{mg} / \mathrm{dL})^{*}$ & $0.79 \pm 0.16$ & $0.83 \pm 0.12$ & 0.332 \\
\hline Uric acid $(\mathrm{mg} / \mathrm{dL})^{*}$ & $4.31 \pm 1.03$ & $4.57 \pm 1.49$ & 0.713 \\
\hline $\mathrm{TSH}(\mathrm{mIU} / \mathrm{mL})^{*}$ & $2.23 \pm 1.58$ & $1.95 \pm 1.19$ & 0.634 \\
\hline Free T4 (ng/dL) ${ }^{*}$ & $1.08 \pm 0.19$ & $1.10 \pm 0.14$ & 0.389 \\
\hline
\end{tabular}

Chi-square test (categorical variables); $t$-test (continuous variables); ${ }^{*} P$ value using Mann-Whitney $U$-test; ${ }^{\ddagger} P<0.05$.

Values given are number of patients (\%) or mean \pm SD.

LDL: low-density lipoprotein; HDL: high-density lipoprotein; hs-CRP: highly sensitive C-reactive protein; SGOT: aspartate transaminase; SGPT: alanine transaminase; $\gamma$ GTP: $\gamma$-glutamyltranspeptidase; TSH: thyroid stimulating hormone.

beneficial effects on the development of hepatic steatosis and obesity-related disorders by targeting the hepatic AMPK [19].

Platycodi Radix has long been used as an expectorant in traditional oriental medicine. Recently, it was reported that Platycodi Radix has anti-inflammatory, antiallergy, antitumor, apoptosis-inducing, and immune-stimulating activities [29-31]. Recently, it was reported that platycodin D, a major saponin component of Platycodi Radix, inhibits fat accumulation and adipogenesis [22, 32-35]. The antiobesity effect of the crude saponins in mice fed a high-fat diet may be due to the inhibition of intestinal absorption of dietary fat by platycodin D [22]. And the antiadipogenic effect of platycodin D involves the upregulation of KLF2 and subsequent downregulation of PPAR $\gamma$ [36]. 
TABLE 2: Changes over time in clinical examination and laboratory investigations between THI and placebo ingestion groups.

\begin{tabular}{|c|c|c|c|}
\hline Variables & $\begin{array}{c}\text { THI } \\
(n=30)\end{array}$ & $\begin{array}{l}\text { Placebo } \\
(n=23)\end{array}$ & $P$ value \\
\hline Weight (kg) & $-1.16 \pm 1.41$ & $-0.24 \pm 1.70$ & $0.036^{\ddagger}$ \\
\hline Body mass index $\left(\mathrm{kg} / \mathrm{m}^{2}\right)$ & $-0.41 \pm 0.55$ & $-0.10 \pm 0.70$ & 0.083 \\
\hline Waist circumference $(\mathrm{cm})^{*}$ & $-1.77 \pm 1.91$ & $-1.04 \pm 2.38$ & 0.156 \\
\hline Hip circumference $(\mathrm{cm})$ & $-1.23 \pm 1.77$ & $-0.71 \pm 1.78$ & 0.304 \\
\hline Waist/hip (\%) & $-0.77 \pm 2.23$ & $-0.46 \pm 2.32$ & 0.628 \\
\hline \multicolumn{4}{|l|}{ Body composition } \\
\hline $\operatorname{Muscle}(\mathrm{kg})^{*}$ & $-0.63 \pm 1.51$ & $-0.06 \pm 0.98$ & 0.151 \\
\hline Fat $(\mathrm{kg})$ & $-0.50 \pm 1.36$ & $-0.38 \pm 1.47$ & 0.761 \\
\hline Fat ratio $(\%)^{*}$ & $-0.06 \pm 1.82$ & $-0.41 \pm 1.36$ & 0.957 \\
\hline \multicolumn{4}{|l|}{ Blood pressure (mmHg) } \\
\hline Systolic ${ }^{*}$ & $-11.30 \pm 13.92$ & $-5.65 \pm 16.29$ & 0.368 \\
\hline Diastolic & $-8.20 \pm 10.60$ & $-6.00 \pm 11.07$ & 0.466 \\
\hline Blood glucose $(\mathrm{mg} / \mathrm{dL})^{*}$ & $-1.93 \pm 8.05$ & $1.43 \pm 7.26$ & 0.062 \\
\hline Total cholesterol (mg/dL) & $-4.63 \pm 26.84$ & $-9.73 \pm 24.23$ & 0.478 \\
\hline Triglyceride $(\mathrm{mg} / \mathrm{dL})^{*}$ & $-14.96 \pm 59.22$ & $1.43 \pm 48.64$ & 0.647 \\
\hline HDL cholesterol (mg/dL) ${ }^{*}$ & $3.50 \pm 16.99$ & $-2.39 \pm 8.47$ & 0.124 \\
\hline LDL cholesterol $(\mathrm{mg} / \mathrm{dL})^{*}$ & $-3.50 \pm 30.39$ & $-3.56 \pm 20.53$ & 0.628 \\
\hline hs-CRP (mg/L)* & $1.59 \pm 6.25$ & $-1.36 \pm 6.50$ & 0.251 \\
\hline White blood cell count $\left(10^{\wedge} 9 / \mathrm{L}\right)$ & $-0.13 \pm 1.02$ & $-0.42 \pm 1.07$ & 0.328 \\
\hline Hemoglobin $(\mathrm{g} / \mathrm{dL})^{*}$ & $-0.12 \pm 0.51$ & $0.73 \pm 5.24$ & 0.208 \\
\hline Hematocrit $(\%)^{*}$ & $-2.09 \pm 7.30$ & $-1.43 \pm 1.11$ & 0.258 \\
\hline Platelet count $\left(10^{\wedge} 9 / \mathrm{L}\right)$ & $-14.50 \pm 23.21$ & $-5.65 \pm 29.32$ & 0.226 \\
\hline Total protein $(\mathrm{g} / \mathrm{dL})^{*}$ & $-0.15 \pm 1.31$ & $0.00 \pm 0.29$ & 0.240 \\
\hline Albumin $(\mathrm{g} / \mathrm{dL})^{*}$ & $0.04 \pm 0.14$ & $0.02 \pm 0.17$ & 0.483 \\
\hline Total bilirubin $(\mathrm{mg} / \mathrm{dL})^{*}$ & $0.04 \pm 0.14$ & $0.00 \pm 0.33$ & 0.112 \\
\hline Direct bilirubin $(\mathrm{mg} / \mathrm{dL})^{*}$ & $0.01 \pm 0.06$ & $0.01 \pm 0.12$ & 0.568 \\
\hline SGOT (IU/L)* & $-0.26 \pm 6.20$ & $-0.60 \pm 3.47$ & 0.971 \\
\hline SGPT $(\mathrm{IU} / \mathrm{L})^{*}$ & $-0.73 \pm 10.41$ & $-1.13 \pm 5.40$ & 0.869 \\
\hline$\gamma \mathrm{GTP}(\mathrm{IU} / \mathrm{L})^{*}$ & $-1.26 \pm 7.65$ & $1.17 \pm 12.64$ & 0.487 \\
\hline Blood urea nitrogen $(\mathrm{mg} / \mathrm{dL})^{*}$ & $-1.43 \pm 2.80$ & $-1.52 \pm 3.96$ & 0.474 \\
\hline Serum creatinine $(\mathrm{mg} / \mathrm{dL})^{*}$ & $0.03 \pm 0.10$ & $0.00 \pm 0.05$ & 0.223 \\
\hline Uric acid $(\mathrm{mg} / \mathrm{dL})^{*}$ & $-0.09 \pm 0.59$ & $-0.10 \pm 0.63$ & 0.621 \\
\hline TSH $(\mathrm{mIU} / \mathrm{mL})^{*}$ & $0.13 \pm 1.45$ & $-0.14 \pm 1.15$ & 0.680 \\
\hline Free T4 $(\mathrm{ng} / \mathrm{dL})^{*}$ & $0.08 \pm 0.35$ & $0.07 \pm 0.31$ & 0.634 \\
\hline
\end{tabular}

$t$-test; ${ }^{*} P$ value using Mann-Whitney $U$-test; ${ }^{\ddagger} P<0.05$.

Values given are number of patients (\%) or mean \pm SD.

LDL: low-density lipoprotein; HDL: high-density lipoprotein; hs-CRP: highly sensitive C-reactive protein; SGOT: aspartate transaminase; SGPT: alanine transaminase; $\gamma$ GTP: $\gamma$-glutamyltranspeptidase; TSH: thyroid stimulating hormone.

In our study, values of mean change of weight during the 2-month treatment in the THI-treated group were $-1.16 \pm 1.41 \mathrm{~kg}$ and in the placebo-treated group were $-0.24 \pm 1.70 \mathrm{~kg}$, respectively. When the mean change in weight in the THI-treated group was compared with that in the placebo-treated group, it was found that the difference in the mean change of weight was statistically significant $(P<0.05)$, but the mean change of weight during the 2-month treatment in the THI-treated group was $-1.16 \pm$ $1.41 \mathrm{~kg}$. Caloric restriction combined with exercise or alone to create a daily energy deficit is the foundation of most weight loss programs. In these programs, many individuals successfully lose at least $4.5 \mathrm{Kg}$ of body weight through behavioral approaches for 6 months [36]. In other studies, the placebo-treated group loses at least $-1.49 \pm 6.19 \mathrm{~kg}$ of body weight during the 2-months [25]. So can we conclude from our study that THI was effective in weight loss?

Our study was conducted in South Korea between November of 2010 to February of 2011, when most Koreans eat and drink more than usual. In addition, the winters in Korea frequently have heavy snowstorms, so our patients did not exercise properly around the time we were completing our 
TABLE 3: Side effects during treatment of THI and placebo.

\begin{tabular}{|c|c|c|c|}
\hline Side effects & $\begin{array}{c}\text { THI } \\
(n=30)\end{array}$ & $\begin{array}{l}\text { Placebo } \\
(n=23)\end{array}$ & $P$ value \\
\hline Anorexia grade $1^{*}$ & 0 & $1(4.3)$ & 0.434 \\
\hline Nausea grade 1 & $5(16.7)$ & $1(4.3)$ & 0.217 \\
\hline Indigestion grade 1 & $8(26.7)$ & $3(13.0)$ & 0.313 \\
\hline Hunger pain grade 1 & $1(3.3)$ & 0 & 1.0 \\
\hline Abdominal pain grade 1 & $1(3.3)$ & 0 & 1.0 \\
\hline Loose stool grade 1 & $2(6.7)$ & $3(13.0)$ & 0.642 \\
\hline Diarrhea grade 1 & $4(13.3)$ & $1(4.3)$ & 0.374 \\
\hline Constipation grade 1 & $2(6.7)$ & $1(4.3)$ & 1.0 \\
\hline Facial edema grade 1 & $1(3.3)$ & 0 & 1.0 \\
\hline Headache grade 1 & $1(3.3)$ & 0 & 1.0 \\
\hline Insomnia grade 1 & $2(6.7)$ & $1(4.3)$ & 1.0 \\
\hline Itching grade 1 & $2(6.7)$ & 0 & 0.499 \\
\hline Fatigue grade 1 & $1(3.3)$ & $1(4.3)$ & 1.0 \\
\hline Palpitation grade 1 & 0 & $1(4.3)$ & 0.434 \\
\hline Satiety grade 1 & $2(6.7)$ & $2(8.7)$ & 1.0 \\
\hline Relieve constipation grade 1 & $5(16.7)$ & $4(17.4)$ & 1.0 \\
\hline Good appetite grade 1 & $1(3.3)$ & $1(4.3)$ & 1.0 \\
\hline Increased gastric acid secretion grade 1 & $1(3.3)$ & 0 & 1.0 \\
\hline Suppression of appetite grade 1 & $3(10.0)$ & $4(17.4)$ & 0.451 \\
\hline Thirst grade 1 & $1(3.3)$ & 0 & 1.0 \\
\hline
\end{tabular}

Chi-square test; ${ }^{*} P$ value using Fisher's exact test.

Values given are number of patients (\%).

Grading scale of Common Terminology Criteria for Adverse Events v3.0 (CTCAE).

study. In our study, even though weight loss was small, THI was statistically significant in its effectiveness on the weight loss.

Prior to this study, THI improved metabolic abnormality in mice that were fed high-fat diets [23]. And the extracts of Platycodi Radix with white balloon flower ameliorated obesity and insulin resistance in obese mice via the activation of AMPK/ACC pathways and reductions of adipocyte differentiation. It also reduced the elevated circulating mediators, including triglyceride, total cholesterol, leptin, resistin, and monocyte chemotactic protein- (MCP-) 1 in obesity [37].

Therefor we expected that THI improved metabolic abnormality with body weight loss in our study. In our study, the values of mean change of triglyceride and HDL cholesterol during the 2-month treatment in the THI-treated group seemed to be improved than those in the placebotreated group. However, those were not statistically significant $(P>0.05)$, because the remedy was a supplement, not a medication, the group was small, the study period was short, and the body reduction effect was too small. We will, therefore, need further research in order to make conclusions about its long-term effects.

However, in our study, values of mean change of platelet count during the 2-month treatment in the THI-treated group seemed to be decreased than that in the placebotreated group. But, that was not statistically significant $(P>$ 0.05). Scuttellaria has antithrombotic and antiplatelet actions that prevent the pathological changes of atherosclerosis and restenosis because it has several chemical compounds. Baicalin has antiproliferative and lipoxygenase-inhibitory activities [38], and Oroxylin A has antithrombotic activities [39]. Also there was a protective effect from Scutellaria baicalensis Georgi on cerebral ischemia injury [40]. So if we studied for a longer time, the result would be statistically significant, and the side effect of bleeding tendency would occur. But in our study the change occurred in normal range.

The adverse drug reactions were indigestion (26.7\%), nausea $(16.7 \%)$, diarrhea (13.3\%), and loose stool (6.7\%). They were mainly gastrointestinal symptoms. These adverse drug reactions may have been due to the body weight lowering effects of the crude saponins, the inhibition of pancreatic lipase activity and intestinal absorption of dietary fat by platycodin D [28]. However, patients who suffered from constipation before the study began felt that the supplement relieved their constipation (16.7\%). In our study, the incidence of subjective and objective adverse drug reactions was insignificant in the THI-treated group compared to the placebo-treated group $(P>0.05)$.

We could not make a capsule or tablet for this study because the THI supplements were $50 \mathrm{~mL}$ of liquid extracts. There can, therefore, be problems for long-term storage.

\section{Conclusion}

In conclusion, the herb extract, a mixture of Scutellariae Radix and Platycodi Radix containing the active ingredients 
Baicalin and Saponin (target herbal ingredient (THI)) was statistically significant in its effectiveness on the weight loss without significant side effects, which was demonstrated by our present randomized, double-blind, and placebocontrolled clinical trial.

\section{Conflict of Interests}

The authors declare that they have no conflict of interests.

\section{Acknowledgments}

This research was supported by a Grant of Biogreen 21 Project (20100301061065001030) from Rural Development Administration of Korea and Sookmyung Women's University 2010 (20100133).

\section{References}

[1] C. D. Brown, M. Higgins, K. A. Donato et al., "Body mass index and the prevalence of hypertension and dyslipidemia," Obesity Research, vol. 8, no. 9, pp. 605-619, 2000.

[2] R. Stamler, J. Stamler, and W. F. Riedlinger, "Weight and blood pressure. Findings in hypertension screening of 1 million Americans," Journal of the American Medical Association, vol. 240, no. 15, pp. 1607-1610, 1978.

[3] E. A. Lew and L. Garfinkel, "Variations in mortality by weight among 750,000 men and women," Journal of Chronic Diseases, vol. 32, no. 8, pp. 563-576, 1979.

[4] B. Larsson, P. Bjorntorp, and G. Tibblin, "The health consequences of moderate obesity," International Journal of Obesity, vol. 5, no. 2, pp. 97-116, 1981.

[5] B. M. Spiegelman and J. S. Flier, "Obesity and the regulation of energy balance," Cell, vol. 104, no. 4, pp. 531-543, 2001.

[6] S. P. Walker, E. B. Rimm, A. Ascherio, I. Kawachi, M. J. Stampfer, and W. C. Willett, "Body size and fat distribution as predictors of stroke among US men," American Journal of Epidemiology, vol. 144, no. 12, pp. 1143-1150, 1996.

[7] M. J. Stampfer, K. M. Maclure, G. A. Colditz, J. E. Manson, and W. C. Willett, "Risk of symptomatic gallstones in women with severe obesity," American Journal of Clinical Nutrition, vol. 55, no. 3, pp. 652-658, 1992.

[8] F. M. Cicuttini, J. R. Baker, and T. D. Spector, “The association of obesity with osteoarthritis of the hand and knee in women: a twin study," Journal of Rheumatology, vol. 23, no. 7, pp. 12211226, 1996.

[9] R. P. Millman, C. C. Carlisle, S. T. McGarvey, S. E. Eveloff, and P. D. Levinson, "Body fat distribution and sleep apnea severity in women," Chest, vol. 107, no. 2, pp. 362-366, 1995.

[10] J. W. Shepard Jr., "Hypertension, cardiac arrhythmias, myocardial infarction, and stroke in relation to obstructive sleep apnea," Clinics in Chest Medicine, vol. 13, no. 3, pp. 437-458, 1992.

[11] R. M. Bostick, J. D. Potter, L. H. Kushi et al., "Sugar, meat, and fat intake, and non-dietary risk factors for colon cancer incidence in Iowa women (United States)," Cancer Causes and Control, vol. 5, no. 1, pp. 38-52, 1994.

[12] P. T. James, R. Leach, E. Kalamara, and M. Shayeghi, "The worldwide obesity epidemic," Obesity Research, vol. 9, 4, pp. 228S-233S, 2001.
[13] H. R. Song, H. S. Park, K. E. Yun et al., "Gender and age differences in the impact of overweight on obesity-related quality of life among Korean adults," Obesity Research and Clinical Practice, vol. 4, no. 1, pp. e15-e23, 2010.

[14] C. L. Ogden, M. D. Carroll, L. R. Curtin, M. A. McDowell, C. J. Tabak, and K. M. Flegal, "Prevalence of overweight and obesity in the United States, 1999-2004," Journal of the American Medical Association, vol. 295, no. 13, pp. 1549-1555, 2006.

[15] World Health Organization, Regional Office For the Western Pacific, International Association For the Study of Obesity, International Diabetes Institute, International Obesity Task Force, The Asia-Pacific Perspective: Redefining Obesity and Its Treatment, Health Communications Australia, 2000.

[16] The third Korea national health and nutrition examination survey (KNHANES V). 2010, The Korea Institute for Health and Social Affairs, 2012.

[17] The Third Korea National Health and Nutrition Examination Survey (KNHANES I ). 1998, The Korea Institute for Health and Social Affairs, 1999.

[18] Clinical Guidelines on the Identification, Evaluation, and Treatment of Overweight and Obesity in Adults, NIH-NHLBI, 1998.

[19] H.-X. Guo, D.-H. Liu, Y. Ma et al., "Long-term baicalin administration ameliorates metabolic disorders and hepatic steatosis in rats given a high-fat diet," Acta Pharmacologica Sinica, vol. 30, no. 11, pp. 1505-1512, 2009.

[20] N. Karu, R. Reifen, and Z. Kerem, "Weight gain reduction in mice fed Panax ginseng saponin, a pancreatic lipase inhibitor," Journal of Agricultural and Food Chemistry, vol. 55, no. 8, pp. 2824-2828, 2007.

[21] J. H. Kim, D. H. Hahm, D. C. Yang, J. H. Kim, H. J. Lee, and I. Shim, "Effect of crude saponin of Korean red ginseng on highfat diet-induced obesity in the rat," Journal of Pharmacological Sciences, vol. 97, no. 1, pp. 124-131, 2005.

[22] L.-K. Han, Y.-N. Zheng, B.-J. Xu, H. Okuda, and Y. Kimura, "Saponins from Platycodi radix ameliorate high fat diet-induced obesity in mice," Journal of Nutrition, vol. 132, no. 8, pp. 22412245,2002

[23] S. Han, K. S. Oh, Y. Yoon et al., "Herbal extract THI improves metabolic abnormality in mice fed a high-fat diet," Nutrition Research and Practice, vol. 5, no. 3, pp. 198-204, 2011.

[24] A. Trotti, A. D. Colevas, A. Setser et al., "CTCAE v3.0: development of a comprehensive grading system for the adverse effects of cancer treatment," Seminars in Radiation Oncology, vol. 13, no. 3, pp. 176-181, 2003.

[25] S. S. Jain, S. J. Ramanand, J. B. Ramanand, P. B. Akat, M. H. Patwardhan, and S. R. Joshi, "Evaluation of efficacy and safety of orlistat in obese patients," Indian Journal of Endocrinology and Metabolism, vol. 15, no. 2, pp. 99-104, 2011.

[26] T. Krakauer, B. Q. Li, and H. A. Young, "The flavonoid baicalin inhibits superantigen-induced inflammatory cytokines and chemokines," FEBS Letters, vol. 500, no. 1-2, pp. 52-55, 2001.

[27] Y. Zhao, H. Li, Z. Gao, and H. Xu, "Effects of dietary baicalin supplementation on iron overload-induced mouse liver oxidative injury," European Journal of Pharmacology, vol. 509, no. 2-3, pp. 195-200, 2005.

[28] H. Lee, R. Kang, Y. Hahn et al., "Antiobesity effect of baicalin involves the modulations of proadipogenic and antiadipogenic regulators of the adipogenesis pathway," Phytotherapy Research, vol. 23, no. 11, pp. 1615-1623, 2009.

[29] K. S. Ahn, E. J. Noh, H. L. Zhao, S. H. Jung, S. S. Kang, and Y. S. Kim, "Inhibition of inducible nitric oxide synthase and 
cyclooxygenase II by Platycodon grandiflorum saponins via suppression of nuclear factor- $\kappa$ B activation in RAW 264.7 cells," Life Sciences, vol. 76, no. 20, pp. 2315-2328, 2005.

[30] C. Y. Choi, J. Y. Kim, Y. S. Kim, Y. C. Chung, K.-S. Hahm, and H. G. Jeong, "Augmentation of macrophage functions by an aqueous extract isolated from Platycodon grandiflorum," Cancer Letters, vol. 166, no. 1, pp. 17-25, 2001.

[31] Y. P. Kim, E. B. Lee, S. Y. Kim et al., "Inhibition of prostaglandin $\mathrm{E}_{2}$ production by platycodin $\mathrm{D}$ isolated from the root of Platycodon grandiflorum," Planta Medica, vol. 67, no. 4, pp. 362364, 2001.

[32] H. L. Zhao, J.-S. Sim, S. H. Shim, Y. W. Ha, S. S. Kang, and Y. S. Kim, "Antiobese and hypolipidemic effects of platycodin saponins in diet-induced obese rats: evidences for lipase inhibition and calorie intake restriction," International Journal of Obesity, vol. 29, no. 8, pp. 983-990, 2005.

[33] J.-Y. Kim, K.-D. Moon, K.-I. Seo et al., "Supplementation of sk1 from platycodi radix ameliorates obesity and glucose intolerance in mice fed a high-fat diet," Journal of Medicinal Food, vol. 12, no. 3, pp. 629-636, 2009.

[34] H. Lee, R. Kang, S. H. Cho, S. Kim, Y. Kim, and Y. Yoon, "Effects of platycodin D on gene expressions of pro-adipogenic and antiadipogenic regulattors in 3T3-L1 cells," Journal of Life Science, vol. 19, no. 12, pp. 1802-1807, 2009.

[35] H. Lee, R. Kang, Y. Shik Kim, S.-I. Chung, and Y. Yoon, "Platycodin D inhibits adipogenesis of 3T3-L1 cells by modulating kruppel-like factor 2 and peroxisome proliferator-activated receptor $\gamma$," Phytotherapy Research, vol. 24, no. 2, pp. S161-S167, 2010.

[36] D. Laddu, C. Dow, M. Hingle, C. Thomson, and S. Going, "A review of evidence-based strategies to treat obesity in adults," Nutrition in Clinical Practice, vol. 26, no. 5, pp. 512-525, 2011.

[37] C. E. Lee, H. J. Hur, J. T. Hwang et al., "Long-term consumption of platycodi radix ameliorates obesity and insulin resistance via the activation of AMPK pathways," Evidence-Based Complementary and Alternative Medicine, vol. 2012, Article ID 759143, 11 pages, 2012.

[38] H.-C. Huang, H.-R. Wang, and L.-M. Hsieh, "Antiproliferative effect of baicalein, a flavonoid from a Chinese herb, on vascular smooth muscle cell," European Journal of Pharmacology, vol. 251, no. 1, pp. 91-93, 1994.

[39] S. K. Ku, I. C. Lee, and J. S. Bae, "Antithrombotic activities oforoxylin a in vitro and in vivo," Archives of Pharmacal Research. In press.

[40] Y. Zhang, X. Wang, X. Wang et al., "Protective effect of flavonoids from Scutellaria baicalensis Georgi on cerebral ischemia injury," Journal of Ethnopharmacology, vol. 108, no. 3, pp. 355-360, 2006. 


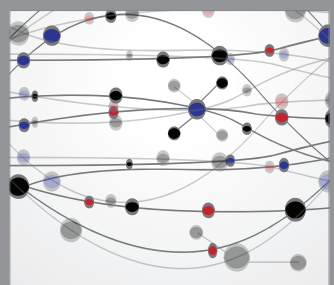

The Scientific World Journal
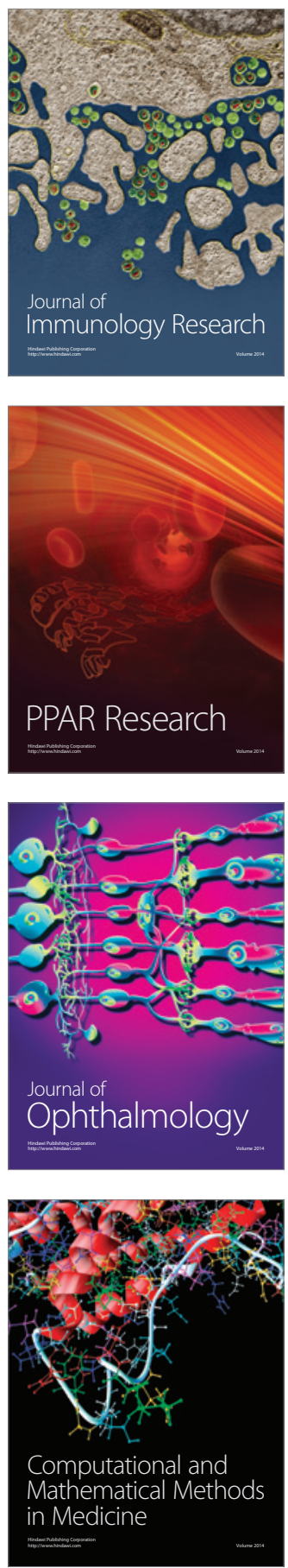

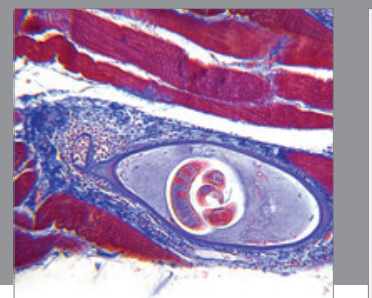

Gastroenterology

Research and Practice
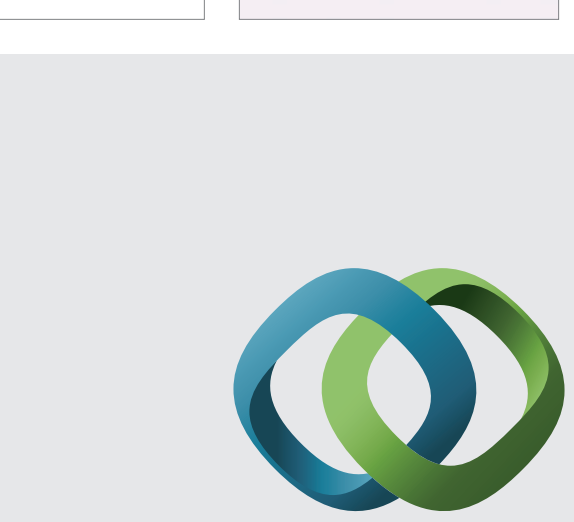

\section{Hindawi}

Submit your manuscripts at

http://www.hindawi.com
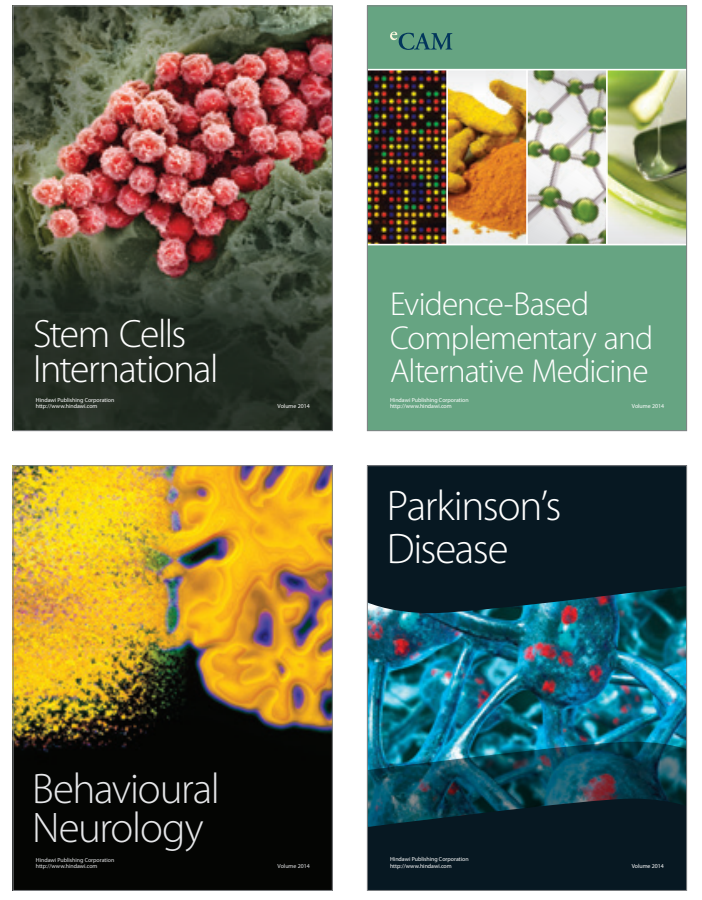
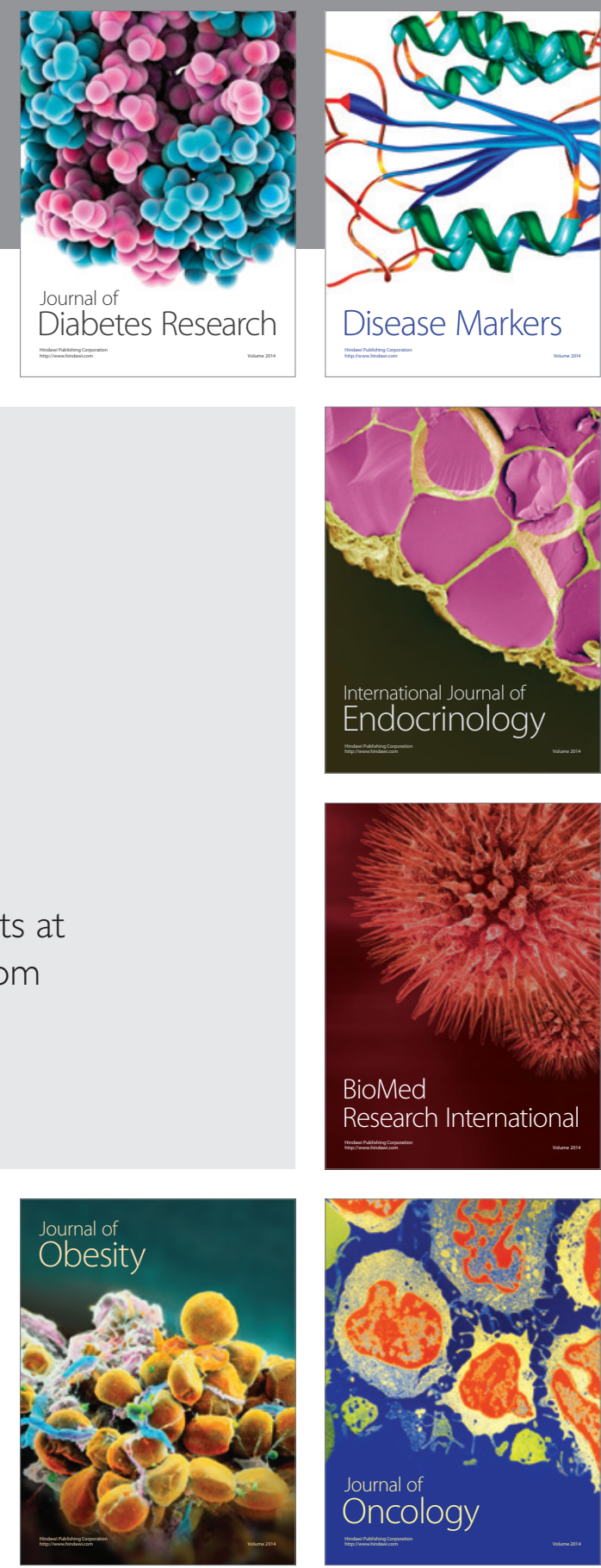

Disease Markers
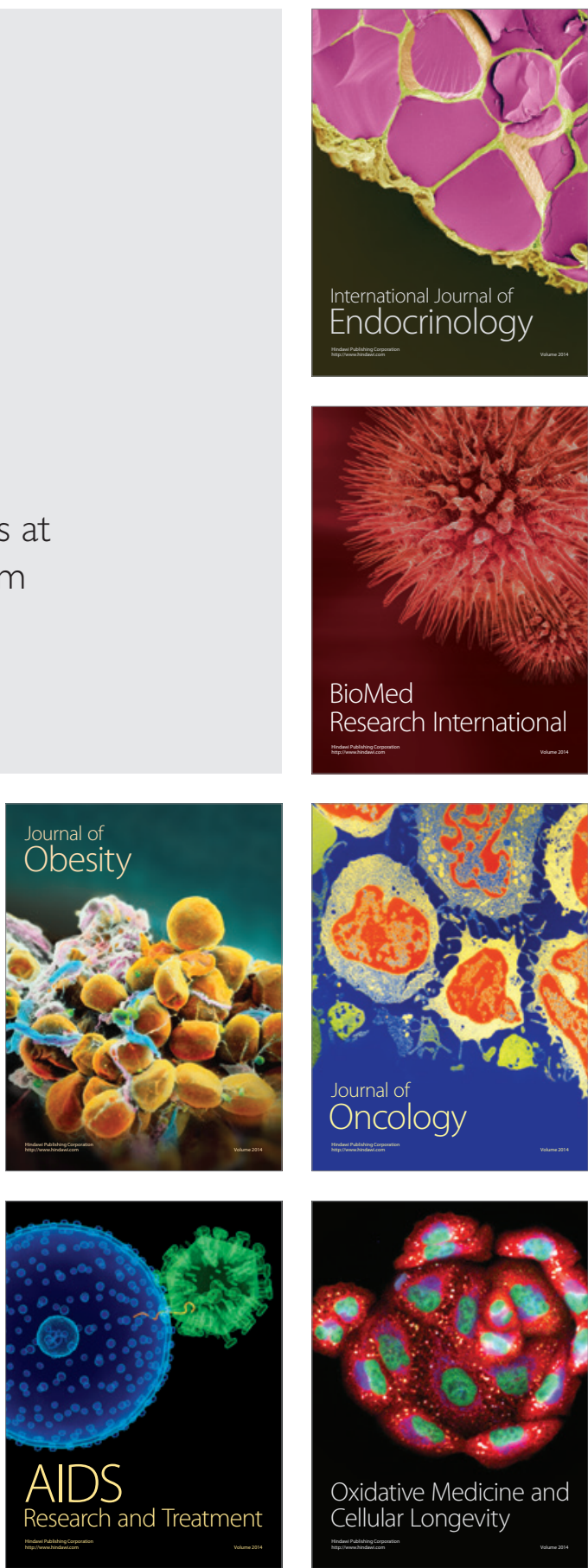